\title{
1932: ENTRE A IMAGEM E A VIRTUALIDADE
}

\author{
Christy Beatriz Najarro Guzmán \\ UFSC/CAPES
}

\begin{abstract}
RESUMO: Entre a realidade e sua representação imagética, intervém a subjetividade de quem capta essa realidade, cujas condições intelectuais, sociais e culturais se articulam para a configuração analógica e dessemelhante do rosto imagético, conforme as considerações de Jacques Rancière sobre a natureza das imagens. Nesse sentido, não só se contesta a existência de um discurso único sobre um evento histórico, mas também a univocidade de tal evento. Levando isso em consideração, 0 documentário 1932: cicatriz en la memoria (2005), dirigido por Carlos Henríquez Consalvi, para 0 Museo de la Palabra y la Imagen (MUPI) de El Salvador, apresenta uma narrativa que compreende 0 levante popular e etnocídio cultural de 1932, como a semente do Partido Comunista (PC) salvadorenho, a mesmo tempo em que na entrelinha se tece uma contra-narrativa, cuja linha de pensamento vai no sentido contrário, colocando o indígena como protagonista, contestando 0 discurso oficial sobre os eventos.
\end{abstract}

PALAVRAS-CHAVE: El Salvador 1932. Realidade. Imagem.

\section{2: BETWEEN IMAGE AND VIRTUALITY}

ABSTRACT: Between reality and its image representation, the subjectivity of who captures this reality interferes, the subjectivity of whose intellectual, social and cultural conditions are configured in face of the imagistic face's analogic and dissimilar arrangement, according to Jacques Rancière's considerations on the images' nature. Therefore, the statement of the existence of a single speech about an historical event is shaken, as well as the univocality of such an event. Taking this into consideration, the documentary 1932: cicatriz en la memoria (2005), directed by Carlos Henríquez Consalvi for the Museo de la Palabr y la Imagen (MUPI), of El Salvador, presents a narrative that grasps the popular cleansing and cultural ethnocide of 1932 as the seed of the Salvadoran Communist Party (PC). At the same time, another narrative whose line of thought goes in the opposite direction is elaborated, placing the indigenous as the protagonist, challenging the official discourse about the events.

KEYWORDS: El Salvador 1932. Reality. Image.

Christy Beatriz Najarro Guzmán é Doutoranda em Literatura pela Universidade Federal de Santa Catarina. 


\title{
1932: ENTRE A IMAGEM E A VIRTUALIDADE
}

\author{
Christy Beatriz Najarro Guzmán
}

O documentário não estaria mais próximo da realidade que a ficção. Nem estaria mais próximo da realidade que da ficção.

Luiz A. Rezende, Documentário e representação

Numa era em que a virtualidade tomou conta do cotidiano dos sujeitos; em que tomamos por "real" aquilo que poderia ser apenas um simulacro, se faz premente refletir sobre a natureza daquelas expressões de pensamento que problematizam ou se apresentam desde uma natureza híbrida. Antes de prosseguir na análise, vale a pena se perguntar se é possível afirmar que há uma realidade pura e objetiva e uma ficção que toma desta realidade elementos para se constituir. É justamente essa questão que se encontra na epígrafe que abre este artigo, a partir da construção de um filme documentário. Visto que a afirmação de Luiz Resende coloca a ficção tão próxima da realidade quanto a expressão documental. Dessa forma, a epígrafe é um convite ao questionamento da dicotomia-realidade, materializada na elaboração documental, e do que seria seu oposto complementar: a ficção.

Como o interesse deste artigo não é, a priori, uma reflexão acerca da natureza da realidade ${ }^{1}$, mas sobre a elaboração de pensamento, através de uma técnica e estética específica - o documentário - , a reflexão estará focada nas implicações políticas do fazer estético e, em última instância, perceber como as técnicas da reprodução imagética estariam implicadas em desvendar uma realidade ou criá-la. Dessa forma diferenciamos dois tipos de filme: o de ficção - categoria nada simples, pois encerra particularidades específicas de fabulação - e, o filme documental, cuja pretensão estética está ou estaria ligada a uma apresentação de uma realidade, cuja orquestração narrativa compartilha algumas características com o cinema de ficção. Para tanto, analisarei o documentário 1932: cicatriz en la memoria (2005), reali-

\footnotetext{
${ }^{1}$ Embora o foco não seja o de refletir sobre a natureza do que é a "realidade", esta discussão está implícita no questionamento da veracidade/fidelidade do documentário com o espaço real-factual.
} 
zado por Carlos Henríquez Consalvi para o Museo de la Palabra y la Imagen de El Salvador.

DOCUMENTANDO A VIDA... ESPÉCULO DO DUPLO DA VIDA...

La memoria toma la palabra

Carlos Henríquez Consalvi, 1932: una cicatriz en la memoria

En los minutos de la arena creo sentir el tiempo cósmico: la historia que encierra en sus espejos la memoria o que ha disuelto el mágico Leteo.

Jorge Luis Borges, El reloj de arena

Em 22 de janeiro de 1932 um grupo de indígenas e camponeses armados de varas de madeira faz o levante popular contra o governo general Maximiliano Hernández Martínez, que terminaria com a extinção de quase 30,000 indígenas. Dentro das reivindicações se encontrava a devolução das terras das quais foram expropriados pelas leis de extinção das terras ejidales $e$ comunales em prol da nação cafeeira, durante a administração de Rafael Zaldívar entre 1881 e 1882. Além disso, exigia-se melhoria na jornada de trabaIho e salários mais justos.

Em função de um analfabetismo generalizado e por afinidades reivindicativas, os líderes indígenas e camponeses decidiram se aliar ao movimento comunista nascente do país, materializado no Socorro Rojo Internacional, organização criada pela Comitern Internacional em 1922 para contribuir com a difusão e formação da militância comunista mundial. Esse quadro evidencia a complexidade do evento de 1932, pois reúne uma diversidade de atores: indígenas, como Casique Feliciano Ama; camponeses, trabalhadores urbanos e intelectuais universitários de militância comunista, como Alfonso Luna, Mario Zapata e Farabundo Martí. ${ }^{2}$

Nesse sentido, o ano de 1932 apresenta-se para muitos intelectuais como uma pegada na areia no deserto: ela está aí, permanece, porém não é palpável. Assim, após os acordos de paz de Chapultepec de 1992, ponto final da guerra civil salvadorenha (1980-1992), inúmeros estudos e reflexões colo-

\footnotetext{
${ }^{2}$ MINED. Historia I El Salvador. San Salvador: Ministerio de Educación (MINED), 2009.
} 
cam o etnocídio cultural ${ }^{3}$ de 1932 como o evento fundador da identidade não só salvadorenha, mas revolucionária do país, esquecendo as conjunturas e singularidades do levantamento campesindio. ${ }^{4}$

É dentro desse marco que o documentário 1932: cicatriz en la memoria (2005) pretender apresentar os acontecimentos do levante mencionado e seus possíveis desdobramentos durante o período ditatorial e de guerra civil. O documentário é conduzido por uma voz narradora, pretensamente "neutra" e, a partir dela, entende o levante popular de 1932 como a semente do partido comunista salvadorenho. Narrativa elaborada pela comunidade intelectual tanto da direita como da esquerda salvadorenha. Além disso, a filmagem conta com a música tradicional, o Xuc, música indígena salvadorenha. Seu nome é derivado da palavra suque, instrumento com o qual se tocava antes e durante a colônia até sua proibição. Foi redescoberta pelo músico Francisco Palaviccini em 1949. Sendo rebatizada sob o nome Xuc música folklórica, anima as festas patronais dos povoados do interior, nas quais se homageia 0 camponês e o índio da região a partir da teatralização de algumas temáticas. ${ }^{5}$ Este tipo de trilha sonora permite uma identificação do espectador com as personas que estão sendo documentadas, visto que, o documentário também conta com as vozes dos envolvidos nos movimentos de libertação daquele ano.

${ }^{3}$ O filósofo salvadorenho Ricardo Martínez entende o massacre de 22 de Janeiro de 1932, perpetrado pelo general Maximiliano Hernández Martínez, presidente na época, para além da violência evidente e o batiza como "genocídio cultural", a partir das considerações da promulgação da ONU a respeito dos diversos massacres perpetrados na América Latina ao longo do século XX. Esta categoria não só contempla o evento trágico em si mesmo (o massacre de mais de 30,000 campesinos e indígenas após um levantamento, cujas prerrogativas principais eram a devolução das terras às comunidades indígenas e o aumento salarial do nascente proletariado), mas também as condições para acontecimento e suas implicações culturais posteriores: a perseguição de indivíduos que falassem ou portassem indumentária indígena após a matanza, logo durante todo o período ditatorial. Cf. MARTíNEZ, Ricardo Martínez. El genocidio cultural de 1932: narrativas y memorias de la represión. Dissertação (mestrado em filosofia). Facultad de filosofía, Universidad Centroamericana José Simeón Cañas, El Salvador, 2010.

${ }^{4}$ Pablo Benítez, em sua conferência "Los únicos verdaderos apóstoles de Cristo: cofradías y guachivales en la insurreción de 1932" (realizada e assistida no dia 27 de Janeiro de 2016 na biblioteca da Assembleia legislativa de El Salvador e não disponível em vídeo ou qualquer outro suporte) afirmou que a forma mais cabal de se referir aos participantes do levante popular é através do termo campesindio, cunhado pelo antropólogo mexicano nas suas pesquisas sobre América Latina, pois designa tanto o caráter camponês como indígena da revolta.

${ }^{5}$ Cf. UTATLÁN, Grupo. Formación musical: primer semestre. Guatemala: Instituto guatemalteco de educación radiofónica, 2009. 
Duas problemáticas emergem disso: a primeira está relacionada a uma apropriação oportunista e silenciadora do evento por parte não só da esquerda, mas também da direita, elaborando uma narrativa comunista do evento de 1932, isto é, o levante popular seria apenas a expressão de um movimento comunista nascente que teve contribuição indígena, deixando na escuridão o evidente caráter étnico e pouco comunista do levante; já a segunda diz respeito ao entendimento do documentário como uma espécie de janela que permite o acesso a uma realidade objetiva que está no passado. Ambas estão imbricadas entre si, formando parte do paradoxo da imagem, seja esta de caráter visual ou não. A esse respeito Jacques Rancière elabora uma longa reflexão sobre a natureza das imagens, cuja argumentação parte da definição em que:

Há um visível que não produz imagem, há imagens que estão todas em palavras. Mas o regime mais comum da imagem é aquele que põe em cena uma relação do dizível com o visível, uma relação que joga ao mesmo tempo com sua analogia e sua dessemelhança. Essa relação não exige de forma alguma que os dois termos estejam materialmente presentes. O visível se deixa dispor em tropos significativos, a palavra exibe uma visibilidade que pode cegar. ${ }^{6}$

O autor ressalta a plasticidade da imagem, cuja natureza pode ser materialmente visível ou pode emergir da palavra. No entanto, afirma que a construção imagética está no jogo que se estabelece entre o visível e o dizível, o que quer dizer que a imagem não depende apenas de uma materialidade "visual", pelo contrário ela pode emergir na elaboração de sentido através da palavra, a partir das mais diversas técnicas narrativas, ora para "espelhar" uma realidade ora para embaçá-la, daí que a imagem se construa entre a "analogia e sua dessemelhança", haja vista que o espectador ao se deparar com uma fotografia, uma narrativa romanesca, um filme de ficção ou documentário, tem diante de si seria a representação do objeto, mas também o que difere dele, sua alteridade, pois a captura é um recorte, cuja escolha está mediada por uma visão de mundo, por uma ideologia. Porém, próprio autor ressalta que essas duas características podem não estar "materialmente presentes". Quer dizer que a analogia independe da dessemelhança? O que quer dizer esse "materialmente"?

\footnotetext{
${ }^{6}$ RANCIÈRE, Jacques. O destino das imagens. Rio de Janeiro: Contraponto, 2012.
} 
Quando um objeto se torna material ele passa da esfera das ideias para a esfera do tangível, fazendo-o perceptível ao olho, porém isso não quer dizer que o que não é visível ou perceptível não faça parte de uma realidade subjetiva ou objetiva, mas simplesmente intangível. Poder-se-ia extrair disso que, em relação ao documentário, a imagem se torna analogia de uma realidade, no entanto, também é a sua dessemelhança, aquilo que é silêncio, mas que persiste no discurso. Aqui adentra-se no campo arenoso da conceituação de "realidade" e da "representação": será possível dizer que algo é real e passível de ser representado? Se como afirma $\operatorname{Lacan}^{7}$, tudo é da esfera da linguagem, e linguagem é construção, então poderíamos facilmente afirmar que não há uma realidade objetiva que possa ser capturada pelo olhar de uma câmera. No entanto, há eventos que respondem a conjunturas específicas, isto é, não há como acessar a uma verdade específica, mas ler um evento/imagem a partir de uma presença-ausência.

Retornando ao ponto de partida, na conjunção entre analogia e dessemelhança, podemos nos perguntar: como opera o filme 1932: cicatriz en la memoria?

O documentário, como mencionado anteriormente, pretende apresentar o testemunho dos participantes e/ou oculares, ativos ou não do levante e etnocídio cultural. Para dar peso à sua argumentação, contextualiza a realidade salvadorenha dentro da crise mundial do café em 1929 e o avanço do da comitern internacional, através do Socorro Rojo Internacional. A câmera se desloca de uma panorâmica aérea que vai abrangendo e se aproximando à paisagem de um El Salvador verde, colorido, quase mítico, enquanto a voz narradora pinta um Cuzcatlán pipil ${ }^{8}$, introduzindo a disputa brancos/oligarquia versus índios/oprimidos, o que enaltece o discurso testemunal que arquiteta o discurso documental, fortalecida com o Xuc e mais especificamente uma das músicas que narra o combate entre mouros e cristãos ${ }^{9}$. Essa é uma perspectiva clássica da produção documental, em que o narrador é colocado de "forma conveniente [para] descrever uma situação ou problema,

\footnotetext{
${ }^{7}$ Sabe-se Jacques Lacan aborda ao longo da sua obra a questão da constituição do sujeito a partir da linguagem. Cf. LACAN, Jacques. O seminário, livro três: as psicoses. Rio de Janeiro: Jorge Zahar, 1988.

${ }^{8}$ Cuzcatlán era o nome maya-pipil do território que hoje reconhecemos como El Salvador.

${ }^{9}$ Mouros e cristãos é uma teatralização sincrética entre os eventos: enfrentamento dos últimos árabes judeus e os espanhóis em 1492 e o enfrentamento entre indígenas e espanhóis em 1942.
} 
apresentar um argumento, propor uma solução e, às vezes, evocar um tom ou estado de ânimo poético"10, evocando uma imagem análoga da realidade campesindia da década de 1930, conforme a definição de imagem de Rancière.

Contudo, a dessemelhança vai se construindo aos poucos nos cortes da filmagem, não só na montagem, mas no enquadramento de cada testemunho, por exemplo, o olhar infeliz e de desencanto de alguns dos entrevistados, a ambientação: a casa de cada um dos participantes e/ou descendentes do levante popular apresenta condições precárias de vida. Isso elabora uma contranarrativa no mesmo documentário: se por um lado há uma exaltação do campesindio, a partir da trilha sonora, e de sua luta pela recuperação das terras, por outro emerge o desencanto e a tristeza daquele levantamento de 1932, pois em nenhum momento se observa uma melhora na vida dos participantes. Além disso, ao longo da narrativa documental se tece a trama e a apropriação da causa por parte do nascente partido comunista. Cabe lembrar que, em função de um alto índice de analfabetismo, os capesindios precisavam de "secretários" e "ajuda especializada" para escrever documentos com suas reivindicações, o que causou divergências das comunidades afetadas, pois nem todos os camponeses aceitaram a participação dos "comunistas", eles o não eram "bem vistos" pelos naturais ${ }^{11}$ :

vení amarralo, lo propios comunistas que decían. En la noche se habían ido a meter a Sonsonate y a Izalco y habían hecho grandes robos vedá [verdad]... y... nosotros no sabíamos, porque pues, como éramos particulares pues, porque eso era causa de los naturales, de los más inditos. Y lo que teníamos media sangre casi no habían. Ese (un comunista), salió con un lazo ¿Qué estamos esperando? Ahorquémoslo, matémonslo. (Sotero Linares, 2003) (2) $^{12}$

Por um lado, o testemunho de Sotero Linares evidencia a falta de univocidade dentro do contexto camponês, pois nem todos se identificavam com os indígenas "naturales", nem com a causa comunista. O que quer dizer que não é possível afirmar que o levante foi puramente índio, nem puramente

\footnotetext{
${ }^{10} \mathrm{NICHOLS}$, Bill. Por que as questões éticas são fundamentais para o cinema documentário. In: Introdução ao documentário. Campinas: Papirus, 2005.

${ }^{11}$ Designa-se dessa maneira aos indígenas sem mistura hispânica.

${ }^{12}$ CONSALVI, Carlos Henríquez. 1932: Cicatriz en la memoria.San Salvador: Museo de la Palabra y la Imagen (MUPI), 2005.
} 
proletário. Afirmar que os comunistas e naturales "roubaram", desqualifica o proceder do levantamento. Em virtude dessas discrepâncias o documentário insiste na fusão da causa campesindia com as prerrogativas comunistas. Da mesma forma que Sotero, há no filme outros participantes, ou testemunhos oculares que narram os acontecimentos desde uma perspectiva do desencanto, pois acreditando nos líderes vermelhos, não houve mais do que massacre e perseguição. Por outro lado, há os discursos dos atores ou descendentes dos atores, como os netos de Feliciano Ama, principal líder indígena daquele evento, que legitimam e reclamam para si o levantamento de 1932, como declara Juan Ama, falando um "nós" em vez de "eles se organizaram".

Outro elemento que, no seu silêncio, fala verborragicamente é a diferenciação das vestimentas dos entrevistados: enquanto os filiados a uma linhagem comunista aparecem em casas com paredes de cimento e iluminadas, os camponeses de olhar tristes que, lembram o massacre como o seu silenciamento, continuam vivendo em condições precárias: casa de bahareque, ou seja, construída a partir varas de bambu entrecruzadas e barro, de chão batido. As vestimentas simples dos testemunhantes é simples. Isso aponta para uma duplicidade do documentário em questão: em primeiro lugar, eticamente, traz à tona vozes de quem vivenciou o etnocídio cultural, numa tentativa de resgate étnico da luta de 1932 e, em segundo lugar e por contraste, continua afirmando uma linhagem social-comunista, ao desdobrar o levantamento do início do século até a guerrilha dos anos 1980.

Levando isso em consideração, poder-se-ia afirmar que o paradoxo da imagem (analogia/dessemelhança) carrega em si mesmo a problemática da representação, isto é, a (im)possibilidade de apresentar uma realidade. Assim, Alan Badiou afirma:

Um filme funciona pelo que retira do visível, nele a imagem é primeiro cortada. Nele, o movimento é entravado, suspenso, invertido, paralisado. Mais essencial que a presença é o corte, não apenas pelo efeito da montagem, mas já de imediato pelo do enquadramento e da depuração dominada do visível (...). O cinema é visitação: do que eu teria visto ou ouvido, a ideia permanece enquanto passa. Eis a operação do cinema. Cuja possibilidade é inventada pelas operações próprias de um artista: organizar o afloramento interno ao visível da passagem da ideia. $^{13}$

${ }^{13}$ BADIOU, Alan. Os falsos movimentos do cinema. In: Pequeno manual da instética. São Paulo: Estação liberdade, 2002. 
Nesse sentido, nem o filme de ficção nem o documentário poderiam ser entendidos como representações cabais de uma realidade, visto que eles estão sujeitos aos enquadramentos e aos cortes realizados tanto na decupagem como na montagem das cenas. Esse movimento de corte e montagem, bem pode se tornar transparente, dando a impressão de que "transcreve" a realidade, mas também pode evidenciar sua capacidade de fabulação, frustrando a ação, ou promovendo um dissenso entre o que é dito e o que é visto.

Badiou ressalta que o movimento do cinema não se encontra na sua capacidade de cópia da realidade, pelo contrário, na sua capacidade de afastamento e fabulação, daí que da imagem cinematográfica não radica apenas naquilo que mostra, mas naquilo que escapa e fica como a potência da realidade. Dito de outro modo, a imagem cinematográfica poderia ser entendida como uma máquina dinamizadora de sentidos e de presenças. Por outro lado, o autor afirma que o cinema é "visitação", o que poderia ser compreendido como um olhar para aquilo que já foi, mas que cala o que poderia ter acontecido. Isso não quer dizer que devemos entender a imagem cinematográfica como um enigma que deve ser desvendado, não é de interpretação que Alan Badiou fala, e sim de uma alteridade da imagem, potencializando a desindentidade.

Trazendo isso para a reflexão deste artigo, como poderíamos armar uma leitura do filme? Como articular as vozes de desencanto e a narrativa comunista para trabalhar com as relações entre o visível e o dizível? Ou como articulá-los para construir, a partir de uma aparente analogia (da imagem com a materialidade dos corpos na tela), sua potente dessemelhança?

Como mencionado anteriormente, a trilha sonora tradicionalmente indígena-camponesa e o testemunho direto de quem participou do levante popular de 1932, a documentação das organizações de esquerda apresentadas, contribuem para criar uma imagem do evento daquele momento. Contudo, há uma narrativa paralela que é orquestrada numa entrelinha ou no limiar do pensamento de esquerda e as prerrogativas do levantamento de 1932. O que evidencia o entrecruzamento de uma narrativa comunista, a partir da apropriação por parte do Socorro Rojo Internacional.

Nesse sentido, a memória não só é apresentada, mas também (re)criada e fabulada, visto que, conforme apontara Pablo Benítez, o levantamento foi conformado por uma multiplicidade étnica que, colocá-la apenas como 
"levantamento indígena" e alinhá-lo ao comunismo nascente do começo do século $\mathrm{XX}$, é redutor e simplista. Apesar de que a trilha sonora e as imagens desloquem o espectador a um universo campesindio, não configuraria uma univocidade indígena, pois entre eles havia divergências tanto étnicas como hierárquicas. Isso faz da representação imagética desse filme documentário um conjunto complexo em que a analogia e a dessemelhança atuam para questionar uma narrativa do levante e massacre de 1932.

Assim, o filme documentário pode ser observado a partir de um enquadramento "coerente" do plano, e uma montagem que é regida por uma lógica prévia. Porém, mesmo dentro dessa lógica, o documentário não pode ser entendido como um reflexo e sim espelhamento ou duplicidade de uma realidade múltipla. Assim, Luiz Rezende Filho afirma que

\begin{abstract}
Um conceito que poderia, então, substituir a noção de representação dentro da teoria do documentário é o de virtualização. A noção de virtualização, ao contrário da de representação, não nos faria supor, diretamente, a existência de um sujeito e de um objeto prévios no documentário. $O$ mundo não estaria na posição de "objeto-modelo" previamente dado e definido (como a imagem formada em um quebra-cabeça) que o documentário deseja copiar. Poderíamos entender a "realidade" como um conjunto extenso e indeterminado de virtualidades coexistentes, que se atualizam, segundo determinadas condições, na produção concreta do filme. Como virtualização, o documentário não tem um objeto prévio. Dessa forma, poderíamos passar a entender o papel do documentarista - cujo discurso, ideologia e intensão são, geralmente, considerados preciso e definidos -, não como o de um "manipulador onipotente" de uma realidade previamente dada, mas como o de um entre vários elementos, que deve se integrar aos outros que eventualmente atravessam a virtualidade estabelecida, e que também comporta as suas próprias virtualidades (...). Neste processo, nada preexiste, a não ser uma série de virtualidades desenvolvidas por um campo problemático de questões que alimenta o processo, que o condiciona e que só poderá ser "respondido" pelo próprio processo. ${ }^{14}$
\end{abstract}

No fundo, a questão chave do documentário envolve um questionamento e um entendimento mais amplo da realidade. Ao propor a categoria virtualização e virtualidades Rezende não afirma a existência de uma realidade específica e sim potências de realidade que são concomitantes ou possíveis. Entendendo a realidade como virtualidade, o lugar do documentarista se des-

\footnotetext{
${ }^{14}$ REZENDE, Luiz Augusto Coimbra de. Documentário e representação. 2005. [Comunicação individual do $V$ encontro de Núcleos de Pesquisa da Intercom].
} 
loca e não pode mais "manipular" porque não há matéria a ser manipulada nem veiculada, mas sim uma virtualidade que pode ser dinamizada entre tantas outras. Nesse sentido, a atualização de uma virtualidade não responde a uma veracidade ou fidelidade em relação a um fato, mas à visibilidade de uma possibilidade entre tantas outras. Se o documentário, tem a responsabilidade ético-social para uma comunidade, conforme as reflexões de Bill Nichols, a virtualidade cumpriria melhor esta exigência, visto que, não estaria afirmando uma narratividade única sobre um evento, como o levante e etnocídio cultural de 1932, mas trazendo à tona discursos que ainda não foram contemplados e que no presente formam parte da dicotomia memória-esquecimento e formação de um contexto social.

Levando isso em consideração, o documentário 1932: cicatriz en la memoria se soma a uma série de iniciativas que problematizam o discurso historiográfico oficial da memória genocida do século XX de El Salvador; traz à baila o testemunho de alguns indígenas, pondo em questão a nacionalidade fundadora: a ideia do bom campesindio, isto é, o trabalhador, agricultor que se senta à sombra de uma árvore com um livro. ${ }^{15}$ Contudo, a própria orquestração narrativa impõe uma visão do campesindio comunista, esquecendo outros discursos e elaborando uma nova narrativa, visto que o etocídio de 1932 ainda está pautado no mito da realidade única que deve ser descoberta nas imagens vivas ou documentais.

Mas do que compreender o "o que aconteceu em 1932", o filme nos coloca diante da imagem difusa de uma memória que vive do e para o esquecimento que, se por um lado articula um discurso atravessado pela polarização política da guerra fria (Comunistas versus Direita capitalista oligárquica), por outro, evidencia as fendas nas quais é possível operar outras narrativas a partir de outras vozes, não para impor uma nova verdade, mas para reconhecer que uma identidade não pode ser elaborada se não for pelo que ela carrega de dessemelhante, de outridade.

${ }^{15}$ LARA-MARTÍNEZ, Rafael. En las manos un pequeño país: Política y poética en El Salvador (1884-2004). Revista InterSedes. Costa Rica, n. 6. 